\title{
Technology-enhanced stem (science, technology, engineering, and mathematics) education
}

\author{
Ying-Tien Wu' $\mathrm{W}^{1}$ O. Roger Anderson ${ }^{2}$
}

Published online: 24 July 2015

(C) Beijing Normal University 2015

Over the past decade, STEM education has received increasing attention and also has been widely recognized as one of the major emphases in contemporary science education reform movements. STEM (science, technology, engineering, and mathematics) involves the study of, and coherent integration among, various academic disciplines, especially the four cardinal disciplines of STEM. It has been advocated that STEM education could provide an opportunity for students to develop increasingly important 21 st Century skills, such as complex problem solving, communication, and collaboration (Bybee 2010). Therefore, STEM education is becoming even more important in preparing students for work in the technologically advanced world and is vital for the nation's competitiveness in the global economy (Breiner et al. 2012).

In recent years, many STEM-related instructional materials, curricula, and guidelines for instruction are emerging. While most of the initial attempts in STEM education addressed one or more of the STEM subjects separately, there are increasing advocates for emphasizing connections between or among the subjects in STEM education (Honey et al. 2014). As a result of the prior lack of integration, a great diversity of foci and contexts are often found in STEM-related research. The research contexts of some STEM-related studies may only involve one of the STEM

Ying-Tien Wu

ytwu@cl.ncu.edu.tw

O. Roger Anderson

ora@1deo.columbia.edu

1 Graduate Institute of Network Learning Technology, National Central University, No. 300, Zhongda Rd., Zhongli District, Taoyuan City 32001, Taiwan

2 Mathematics, Science and Technology, Teachers College, Columbia University, 525 W. 120th Street, New York, NY 10027, USA 
disciplines, while other more comprehensive studies may address more and deeper connections among the STEM disciplines.

With the rapid development of information and communication technology, educators and researchers increasingly highlight the potential merits of using educational technology to improve STEM learning outcomes. In Mayo's (2009) review on the learning outcomes for video games in STEM disciplines, it is argued that video games have the potential to be used as a route to large-scale STEM education, but the quality of video games is one of the important unresolved issues in realizing the goal. In their systematic review and meta-analysis, D' Angelo et al. (2013) advocated that there is still much to be learned about the educational benefits of computer simulations across the STEM domains, although the general positive effects are clearly evident in relevant studies. To make STEM education become more effective or efficient, the use of educational technologies, such as online interactive learning environments, digital games, augmented reality (AR), simulations, and robots, should be one of the important topics for researchers in STEM education and educational technology. This special issue aims to offer insights into the current and future trends and research directions in the application of educational technologies in STEM education. Five papers encompassing four empirical studies and one review paper are included. Below is a brief overview of the contributions included in this special issue.

The construct of models and their educational applications have been recognized as one of the important practices of science that should be emphasized in science learning (e.g., Louca et al. 2012; NRC 2012). In the first paper by Papaervripidou and Zacharia, Examining how students' knowledge of the subject domain affects their process of modeling in a computer programming environment, modeling-based learning was implemented in a computer programming environment. This study investigated whether graduate students with different science content knowledge backgrounds, namely physics and science education graduates, developed different modeling competence and constructed different models. Evidence included (1) two paper-and-pencil tests that assessed the participants' content knowledge about 1D collisions and modeling competence, (2) the quality of the participants' created models, and (3) screen-capture data (both video and sound). Furthermore, the study revealed that variation in science background knowledge appears to affect important outcomes such as the learners' modeling competence, the types and nature of the models created, and the model creation progression that they followed.

In online learning environments, the understanding of how to deliver learning content more effectively to students is critical for student better learning outcomes. The second paper by Alforih and Williams, The effect of curriculum organization on the acquisition of abstract declarative knowledge in computer based instructions, aims to design an instructional method that facilitates the teaching of abstract knowledge in the Industrial Engineering curriculum, and to demonstrate its effectiveness through empirical research. The experiment was completed in 8 weeks. A total of 72 undergraduate students were presented with the same abstract knowledge but presented in three different types of organization, including a Bottom Up moving from specific to general information, a Top Down moving from general to more specific information, and unorganized random presentation of 
topics. Another factor that was also introduced is Graphing, which is a method that is believed to improve the learning process. The results suggest that abstract knowledge acquisition is greatly improved when the knowledge is presented in a Bottom-Up hierarchical fashion. On the other hand, neither Graphing nor the Top Down or Unorganized conditions affect learning by these novice students.

For educators and researchers in the STEM education field, transformation of assessment is one of the important issues for the success of STEM education. The third paper by Lin et al., Design of an assessment system for collaborative problemsolving in STEM education, developed an assessment system for evaluating junior high students' collaborative problem-solving (CPS) skills in the context of STEM education. Based on a matrix of CPS proposed by the Organization for Economic Co-operation and Development (OECD), eight assessment modules in STEM education, including problem tasks such as designing shelves, using a microwave oven, and construct a house, were developed. In the online assessment system, a computer collaboration agent, rather than human collaboration agent, was developed and used in this exploratory study. This study further examined the criterionrelated validity of the effectiveness of these modules by collecting 222 junior high students' performance on these modules. The results provided evidence of acceptable difficulty and satisfactory discrimination validity of the assessment system items. Furthermore, consistency in the results of applying the system indicated that this assessment system was adequately effective for evaluating junior high students' CPS skills in STEM education. Also, this study recommended that students' performance in establishing and maintaining team organization should be the focus of future studies.

As advocated by D'Angelo et al. (2013), there is still much to be learned about the educational benefits of computer simulations across the STEM domains. Undoubtedly, simulation-based learning coupled with proper instructional strategies is one of the important relevant research issues. The fourth paper by Srisawasdi and Panjaburee, Exploring effectiveness of simulation-based inquiry learning in science with integration of formative assessment, explores the effect of simulation-based inquiry with formative assessment on ninth graders' conceptual learning of buoyancy-driven phenomena. Using an experimental research design, this study revealed that students who participated in the simulation-based inquiry learning with formative assessment significantly outperformed their counterparts who did not have the same formative assessment experiences. They especially excelled in terms of conceptual understanding, indicating that the integration of formative assessment into simulation-based inquiry learning could effectively improve student comprehensive understanding of science concepts.

As mentioned previously, the use of video or digital games in STEM domains could be an effective route to large-scale STEM education. The fifth paper by Cheng et al., The use of serious games in science education: A review of selected empirical research from 2002 to 2013, systematically reviewed the empirical studies on the use of serious games in science education from 2002 to 2013. Using the science citation index (SCI) and the social science citation index (SSCI) databases as the literature sources, a total of 53 empirical studies were identified as the review targets. These empirical studies were content-analyzed using three major 
dimensions; namely, (1) game features, (2) pedagogy, and (3) research method. Several significant research trends among the empirical studies using serious games in science education were identified, such as (1) knowledge construction was the major learning goal of these serious games used in science educational settings, (2) most of the reviewed studies were concerned with interdisciplinary learning, and (3) relatively fewer studies explicitly introduced the educational theoretical foundations for using serious games in science education, or the instructional strategies coupled with the use of serious games. The educational implications and directions for further research were also discussed in this study.

\section{Conclusion and future studies}

This special issue includes five papers that provide perspectives on the current state of, and trends in, the application of educational technologies in STEM education. Among these papers, four focus on the use of technology in single STEM domains (i.e., individual science or engineering domains), including three empirical papers on learning topics in the physical sciences and engineering (first, second, and fourth papers); addressing in the first, the use of computer programming environments in supporting modeling-based learning; and in the second, designing and examining an instructional method that facilitates the teaching of abstract knowledge in the Industrial Engineering curriculum. The fourth paper addressed integrating formative assessment into simulation-based inquiry learning using buoyancy-based phenomena as the central concept. The third and fifth papers provide a more general perspective on the use of serious games in science education, including the role of collaborative learning in improving real-life engineering and science problemsolving skills, and a review of the way serious games have been examined in science education research, respectively. Moreover, one paper in this special issue is particularly concerned with the development and evaluation of an assessment system for CPS in integrated STEM education contexts (the third paper).

Future research could productively explore how technology can be used to develop learners' knowledge, self-efficacy, and skills in solving interdisciplinary complex problems in the integrated STEM education contexts. Especially, longterm studies addressing this issue are clearly needed. Also further research on analyses of learning processes in individual and group/social contexts should be pursued using strong theoretical frameworks as a way of enhancing our conceptual foundations for computer-based STEM education, and providing a more coherent framework to guide research-based educational applications. In particular, student individual learning behavior patterns could be analyzed with action-based sequential analyses; and student interaction patterns with teachers, peers, and technology could also be analyzed with social network analyses. Given the multimodal, self-paced, and information feedback affordances of computer-based learning, further research on how these qualities of digital-based learning systems can enhance the learning of sometimes complex and multidisciplinary STEM topics deserves more experimental attention. Moreover, the assessment of technology- 
enhanced STEM education could be another important topic to be investigated in future studies.

\section{References}

Breiner, J., Harkness, S., Johnson, C., \& Koehler, C. (2012). What is STEM? A discussion about conceptions of STEM in education and partnerships. School Science and Mathematics, 112(1), 3-11.

Bybee, R. W. (2010). Advancing STEM education: A 2020 vision. Technology and Engineering Teacher, $70(1), 30-35$.

D’Angelo, C., Rutstein, D., Harris, C., Bernard, R., Borokhovski, E., \& Haertel, G. (2013). Simulations for STEM learning: Systematic review and meta-analysis. Menlo Park, CA: SRI International.

Honey, M., Pearson, G., \& Schweingruber, H. (Eds.). (2014). STEM integration in K-12 education: Status, prospects, and an agenda for research. Washington, DC: National Academies Press.

Louca, L., Zacharia, Z. C., \& Constantinou, C. (2012). In quest of productive modeling based learning discourse in elementary school science. Journal of Research in Science Teaching, 48(8), 919-951.

Mayo, M. J. (2009). Video games: A route to large-scale STEM education? Science, 323, 79-81.

National Research Council. (2012). A framework for K-12 science education: Practices, crosscutting concepts, and core ideas. Committee on a Conceptual Framework for New K-12 Science Education Standards. Board on Science Education, Division of Behavioral and Social Sciences and Education. Washington, DC: The National Academies Press.

Ying-Tien Wu is currently an associate professor of Network Learning Technology at National Central University, Taiwan. His research work involves both science education and digital learning, and his research interests include inquiry-based instruction, cognitive structure, reasoning and argumentation, scientific epistemological beliefs, technology-enhanced science learning, the use of gamification in education, and technological pedagogical content knowledge. His research findings have been published in reputable international science education and digital learning journals, such as Science Education, International Journal of Science Education, Research in Science Education, Journal of Computer Assisted learning, and Educational Technology and Society. He also serves as a reviewer for many international academic journals in science education and digital learning.

O. Roger Anderson is a Professor of Natural Sciences and Chair of the Department of Mathematics, Science, and Technology at Teachers College, Columbia University. He is also a Sr. Research Scientist in Biology at the Lamont-Doherty Earth Observatory of Columbia University. He has held both these positions for 50 years. He received his doctoral degree in biology and education from Washington University in St. Louis (1964). He is the former President of the National Association for Research in Science Teaching, and also the International Society of Protistologists. He worked as the editor of the Journal of Research in Science Teaching (1970-1975). 